\title{
IMUNOGENICIDADE DO HERPESVÍRUS BOVINO TIPO 5 (BHV-5) EM VACINAS INATIVADAS DE DIFERENTES FORMULAÇÕES ${ }^{1}$
}

\author{
IMMUNOGENICITY OF BOVINE HERPESVIRUS TYPE-5 VACCINES \\ FORMULATED IN DIFFERENT WAYS
}

\author{
Daniza Coelho Halfen ${ }^{2}$ Telmo Vidor ${ }^{3}$ Fátima Machado Braga ${ }^{4}$ Carlos Willi Van Der Laan ${ }^{5}$
}

\section{RESUMO}

Quatro vacinas inativadas, produzidas com uma amostra do herpesvírus bovino tipo 5 ( $\mathrm{BHV}$-5) isolada de um surto de meningoencefalite no Rio Grande do Sul, foram administradas em quarenta bovinos visando a avaliar a sua capacidade imunogênica. As vacinas A e B foram formuladas com adjuvante oleoso e as vacinas $C$ e $D$ com hidróxido de alumínio [ $\mathrm{Al}_{2}$ $(\mathrm{OH})_{3}$ ]. $\mathrm{O}$ título da suspensão viral utilizada nas vacinas foi de $10^{7,5}$ DICT $_{50} / 25 \mu$ L. Immunostin ${ }^{\circledR}$, um imunoestimulante derivado de Mycobacterium, foi adicionado às vacinas $B$ e D. Após receberem três doses de vacina com intervalos de 30 dias, somente os animais dos grupos A (90\%) e B (100\%) desenvolveram uma resposta sorológica significativa. As respostas sorológicas às vacinas $A$ e $B$ foram ajustadas por regressão linear, demonstrando que os títulos de anticorpos aumentaram significativamente à medida que foram repetindo-se as aplicações das vacinas. O Immunostin ${ }^{\circledast}$ potencializou a capacidade imunogênica da vacina $D$ mas, aparentemente, não foi eficiente na vacina $B$. Concluiu-se que as vacinas inativadas, produzidas a partir de suspensões virais de BHV-5 com títulos altos e com adjuvante oleoso induzem a produção de níveis consideráveis de anticorpos neutralizantes em mais de $80 \%$ dos animais vacinados após a terceira dose.

Palavras-chave: herpesvírus bovino tipo 5 e 1 , (BHV- 5 e $\mathrm{BHV}$ 1), adjuvantes, vacinas.

\section{SUMMARY}

Four inactivated vaccines formulated with a bovine herpesvirus tipe $5(\mathrm{BHV}-5)$ strain isolated from an outbreak of bovine meningoencephalitis in Rio Grande do Sul, Brazil, were administred in forty cattle as to evaluate its immunogenicity. The vaccines $A$ and $B$ used mineral oil and vaccines $C$ and $D$ used aluminum hydroxide $\left(\mathrm{Al}_{2}(\mathrm{OH})_{3}\right)$ as adjuvant. The titer of the viral suspension used in all vaccines was $10^{7.50} \mathrm{TCID}_{50} / 25 \mu \mathrm{l}$. Immunostin $^{\circledR}$, a Mycobacterium derived immunostimulant, was added to vaccines $B$ and $D$. After receiving three doses of vaccines, at 30 days intervals, only the animals of the groups $A$ (90\%) and B (100\%) developed significant antibody titers. The responses to these vaccines were adjusted to linear regression, showing that the antiboby titers increased progressively with the number of immunizations. The use of Immunostin ${ }^{\circledR}$ enhanced the immunogenicity of the vaccine with aluminum hidroxide but was ineffective when associated with oil adjuvants. It was concluded that inactivated $B H V-5$ vaccines prepared with high titer viral suspensions and oil adjuvants induce adequate levels of antibodies in a high proportion of the vaccinees after the third dose.

Key words: bovine herpesvirus 1 and 5, BHV- 5, BHV-1, vaccines.

\section{INTRODUÇÃO}

Os herpesvírus bovinos tipo 1 e tipo 5 (BHV-1 e BHV-5) são importantes patógenos de bovinos, sendo o BHV-1 associado principalmente à enfermidade respiratória e reprodutiva e o BHV-5 responsável por casos de meningoencefalite de curso geralmente fatal (RIET-CORREA et al., 1996). BHV-5, anteriormente classificado como BHV -1.3 (ROIZMAN et al., 1995), é estreitamente relacionado com as cepas respiratórias e genitais do BHV-1. Há extensa similaridade em aspectos biológicos e moleculares entre os dois vírus e homologia de nu-

\footnotetext{
${ }^{1}$ Parte da Dissertação de Mestrado apresentada pelo primeiro autor para obtenção do grau de Mestre em Veterinária na Faculdade de Veterinária da Universidade Federal de Pelotas (UFPel), Pelotas, RS.

${ }^{2}$ Médico Veterinário, MSc, Professor Adjunto, Departamento de Ciências Biomédicas, Universidade de Caxias do Sul, RS.

${ }^{3}$ Médico Veterinário, Dr., Professor Adjunto, Laboratório de Virologia e Imunologia, Faculdade de Veterinária, UFPel, 96010-900, Pelotas, RS. Autor para correspondência.E-mail: tvidor@ufpel.tche.br.

${ }_{5}^{4}$ Médico Veterinário, MSc, Professor Adjunto, Laboratório de Virologia e Imunologia, Faculdade de Veterinária, UFPel.

${ }^{5}$ Médico Veterinário, MSc., Laboratório de Virologia e Imunologia, Faculdade de Veterinária, UFPel.
} Recebido para publicação em 02.06.99 Aprovado em 01.03.00 
cleotídeos e aminoácidos superior a 85\% (FLORES et al., 1998). Significativas reações sorológicas cruzadas ocorrem entre o BHV-1 e BHV-5. Somente com a utilização de anticorpos monoclonais e técnicas moleculares é possível fazer a distinção entre os dois vírus (ROEHE $\boldsymbol{e t} \boldsymbol{a l} .$, 1998). As principais diferenças entre o BHV-1 e o BHV-5 referem-se às características clínico-epidemiológicas e ao potencial neurotrópico do BHV-5 (FLORES et al., 1998). O BHV-1 tem sido isolado no Brasil desde 1978 (ALICE), com surtos subseqüentes de rinotraqueíte, balanopostite e vulvovaginite, descritos em diversas regiões do Brasil (MULLER et al., 1979; NOGUEIRA et al., 1986, WEIBLEN et al., 1991; HALFEN et al., 1995 ). Surtos de meningoencefalite pelo BHV-5 foram diagnosticados inicialmente no Rio Grande do Sul em 1989 (RIET-CORREA et al., 1989; WEIBLEN et al., 1989), e desde então a enfermidade tem sido detectada no Mato Grosso do Sul, São Paulo, Paraná e Rio de Janeiro (ROEHE $\boldsymbol{e t}$ al., 1998).

Evidências sorológicas indicam que $o$ BHV-1 está distribuído por todo o País, com percentuais de animais soropositivos variando de $20 \%$ a $80 \%$ nas propriedades examinadas (ANUNCIAÇÃO et al., 1989; LOVATO $\boldsymbol{e t}$ al., 1995; VIDOR $\boldsymbol{e t}$ al., 1995; KUNG et al., 1996). A prevalência de infecções pelo BHV-5 ainda é desconhecida, mas devido à extensa reatividade cruzada entre os dois vírus, estima-se que uma considerável parcela dos bovinos supostamente infectados pelo BHV-1 pode ser soropositivo para BHV-5 (ROEHE et al., 1998). O diagnóstico de meningoencefalite pelo BHV-5 tem aumentado consideravelmente nos últimos anos, com índices de mortalidade próximos a $100 \%$. Esses fatos demonstram a necessidade de um programa de controle para essa virose, sendo a vacinação, um dos métodos propostos.

Considerando-se a similaridade entre os dois vírus, a produção de vacinas inativadas contra o BHV-5, com a mesma tecnologia utilizada para o BHV-1, é apontada como uma alternativa para o controle dos surtos de meningoencefalite por BHV5. Embora não impeça a infecção, a vacinação reduz a incidência da doença e a excreção de partículas virais infecciosas (ZUFFA \& FEKETEOVÁ, 1980; FENNER et al., 1993; ROMERA et al., 1998). O uso de adjuvantes, assim como a adição de imunoestimulantes são indicados para aumentar a imunogenicidade das vacinas inativadas, buscando uma resposta imunológica mais potente e duradoura (ZUFFA et al., 1985; FERNANDEZ, 1993; FENNER et al., 1993; ROMERA et al., 1998).

O presente trabalho foi realizado visando a avaliar a capacidade imunogênica de uma amostra de BHV-5, em quatro vacinas inativadas com diferentes formulações.

\section{MATERIAL E MÉTODOS}

O experimento foi conduzido numa propriedade do município de Pelotas, RS, utilizando-se 40 bovinos, de ambos sexos, com idade entre 8 e 24 meses, sem raça definida, soronegativos para BHV-1 e BHV-5. Os animais foram divididos em quatro grupos de dez, mantidos junto com o restante do rebanho, em regime de criação extensiva em campo nativo. Cada grupo recebeu três doses de $3 \mathrm{ml}$ de vacina, com intervalo de trinta dias entre cada dose, sendo denominados A, B, C, e D, de acordo com a vacina recebida. As coletas de sangue para sorologia foram realizadas nos dias $1,30,37,44,51$ e 90 do experimento. $\mathrm{O}$ grupo controle foi representado por animais do rebanho que não receberam a vacina, testados sorologicamente para o BHV-1 em todas as etapas do experimento. As vacinas com adjuvante oleoso foram inoculadas por via intramuscular profunda e as vacinas com adjuvante hidróxido de alumínio por via subcutânea.

Quatro vacinas inativadas foram utilizadas, duas com adjuvante oleoso (vacinas A e B) e duas com hidróxido de alumínio (vacinas $\mathrm{C}$ e $\mathrm{D}$ ), elaboradas a partir de suspensão de BHV-5, com título de $10^{7.5}$ DICT ${ }_{50} / 25 \mu$ l, calculado pelo método Behrens \& Karber (MAYR et al., 1982), produzida em células Madin Darby Bovine Kidney (MDBK - ATCC). A amostra de BHV-5 foi isolada em cultivo primário de testículo de terneiro, preparado segundo MAYR \& GUERREIRO (1981), a partir de secções de cérebro bovino proveniente de um rebanho que apresentou surto de meningoencefalite no município de Pelotas, RS. A suspensão viral vacinal foi inativada com binari etilenemine (BEI), obtida pela ciclização do 2- Bromoetilamine (BEA), sob condições alcalinas por uma hora a $37^{\circ} \mathrm{C}$. O controle de vírus residual foi feito através da inoculação e observação da presença/ausência de efeito citopático em cultivos de células MDBK.

O adjuvante oleoso foi preparado com óleo mineral (nove partes de Marcol 52 - Esso Standard Oil Co.) e uma parte de Montanide 888 ( Sepic Co. Paris, França) como emulsificante. $\mathrm{O}$ adjuvante hidróxido de alumínio (Laboratório Leivas Leite Pelotas, RS) foi preparado na diluição 1:5, utilizando-se Meio Mínimo Essencial de Eagle - (Cultilab) como diluente. Nas vacinas B e D foi adicionado Immunostin (Vetrepharm Inc.), um imunoestimulante derivado de Mycobacterium. As vacinas foram produzidas segundo técnica recomendada por VIDOR (1995). A composição final das vacinas está apresentada na tabela 1 .

As vacinas com adjuvante $\mathrm{Al}_{2}(\mathrm{OH})_{3}$ foram mantidas em agitação por $4 \mathrm{~h}$, para proporcionar uma eficiente adsorção do antígeno. As vacinas oleosas 
Tabela 1 - Composição de cada dose de quatro vacinas inativadas produzidas contra o herpesvírus bovino -5 .

\begin{tabular}{|c|c|c|c|c|c|c|}
\hline Vacina & Antígeno & $\begin{array}{c}\text { Título viral } \\
\text { Total }\end{array}$ & Diluente & Adjuvante & Immunostin $^{(}$ & $\begin{array}{l}\text { Volume } \\
\text { Total }\end{array}$ \\
\hline A & $1,5 \mathrm{ml}$ & $10^{9.25} / \mathrm{ml}$ & não & $\begin{array}{c}1,5 \mathrm{ml} \\
\text { marcol -montanide }(9: 1) \\
1,45 \mathrm{ml}\end{array}$ & não & $3 \mathrm{ml}$ \\
\hline B & $1,5 \mathrm{ml}$ & $10^{9.25} / \mathrm{ml}$ & não & marcol - montanide $(9: 1)$ & $0,05 \mathrm{ml}(1 \mu \mathrm{g})$ & $3 \mathrm{ml}$ \\
\hline $\mathrm{C}$ & $1,5 \mathrm{ml}$ & $10^{9.25} / \mathrm{ml}$ & $1,2 \mathrm{ml}$ & $0,3 \mathrm{ml}-\mathrm{Al}_{2}(\mathrm{OH})_{3}$ & não & $3 \mathrm{ml}$ \\
\hline $\mathrm{D}$ & $1,5 \mathrm{ml}$ & $10^{9.25} / \mathrm{ml}$ & $1,15 \mathrm{ml}$ & $0,3 \mathrm{ml}-\mathrm{Al}_{2}(\mathrm{OH})_{3}$ & $0,05 \mathrm{ml}(1 \mu \mathrm{g})$ & $3 \mathrm{ml}$ \\
\hline
\end{tabular}

foram emulsionadas com emulsificador de mesa, desenvolvido por VIDOR (1995), e submetidas a testes de esterilidade para avaliar possível contaminação por bactérias e fungos. A inocuidade foi testada nos animais vacinados, através de exames clínicos nos dias subseqüentes às vacinações.

As amostras de soro foram testadas por soroneutralização (SN) para quantificação de anticorpos, segundo técnica de HOUSE \& BACKER (1971), utilizando-se microplacas de fundo chato. Os testes foram realizados frente a cepa padrão Los Angeles de BHV-1.

O delineamento experimental foi em classificação dupla, comparando os fatores vacina e coleta. A variável analisada foi a média dos títulos de anticorpos em logaritmo na base 2. Foi realizado teste de diferenças mínimas significativas (Teste de Duncan), para comparar as médias de todas as vacinas. As análises foram feitas através do Sistema de Análise Estatística - SANEST ( ZONTA et al., 1984).

\section{RESULTADOS}

Os resultados dos testes sorológicos realizados após as vacinações demonstraram que $90 \%$ dos animais que receberam a vacina $\mathrm{A}$, e $100 \%$ dos animais que receberam a vacina $B$, desenvolveram títulos de anticorpos iguais ou superiores a $3 \log 2$ após a terceira dose vacinal (Tabela 3). As vacinas $\mathrm{C}$ e D induziram títulos de anticorpos neutralizantes dessa magnitude após três doses vacinais em apenas $10 \%$ e $60 \%$ dos animais vacinados, respectivamente.

Os títulos médios de anticorpos neutralizantes (expressos em $\log 2$ ) produ-

\section{DISCUSSÃO} pelos animais vacinados.

${ }^{\mathrm{a} T i ́ t u l o ~ e m ~ L o g 2 ~}$ zidos pelos bovinos após a terceira dose vacinal foram de 4,6 para a vacina $A, 4,5$ para a vacina $B, 0,7$ para a vacina $\mathrm{C}$ e 2,9 para a vacina D. Os títulos de anticorpos produzidos pelos animais vacinados foram baixos nas primeiras coletas e aumentaram sensivelmente após a terceira dose vacinal (Tabela 2). A adição de Immunostin $^{\circledR}$ aumentou resposta vacinal em aproximadamente $10 \%$ dos animais que receberam a vacina oleosa $\mathrm{B}$, e em $50 \%$ dos animais que receberam a vacina com adjuvante $\mathrm{Al}_{2}$ $(\mathrm{OH})_{3} \mathrm{D}$.

Nenhuma alteração clínica foi observada nos animais vacinados, confirmando a inocuidade das vacinas. Não foi detectada infectividade residual nas suspensões vacinais e os testes de bacteriologia e micologia foram negativos. Os títulos médios de anticorpos e a porcentagem de animais que desenvolveram títulos de anticorpos, iguais ou maiores a 3 Log2, podem ser observados nas tabelas 2 e 3 respectivamente. A figura 1 apresenta a evolução da resposta a cada vacina durante o experimento.

O controle de infecções por herpesvírus como o BHV-1 é baseado principalmente na imunização com vacinas inativadas ou vacinas vivas modificadas. As vacinas inativadas são extensivamente utilizadas nos países onde o BHV-1 é enzoótico, como um instrumento para o controle dessa virose (FENNER $\boldsymbol{e t}$ al., 1993; FERNANDEZ, 1993). Essas vacinas são inócuas, não oferecendo risco de indução de abortos e infertilidade ou reversão à virulên-

Tabela 2: Títulos médios de anticorpos neutralizantes contra o herpesvírus bovino-5 produzidos

\begin{tabular}{|c|c|c|c|c|c|}
\hline \multirow[t]{2}{*}{ Vacina } & \multicolumn{5}{|c|}{ Coleta } \\
\hline & $\begin{array}{c}1^{\underline{a}} \\
30 \text { dias após }^{\text {a } 1^{\underline{a}} \text { dose }}\end{array}$ & $\begin{array}{c}2^{\mathrm{a}} \\
07 \text { dias após } \\
\text { a } 2^{\mathrm{a}} \text { dose }\end{array}$ & $\begin{array}{c}3^{3^{\mathrm{a}}} \\
14 \text { dias após } \\
\text { a } 2^{\underline{a}} \text { dose }\end{array}$ & $\begin{array}{c}4^{\underline{\mathrm{a}}} \\
21 \text { dias após } \\
\text { a } 2^{\underline{a}} \text { dose }\end{array}$ & $\begin{array}{c}5^{\mathrm{a}} \\
30 \text { dias após a } \\
3^{\mathrm{a}} \text { dose }\end{array}$ \\
\hline $\begin{array}{c}\text { A } \\
\text { Adjuvante oleoso }\end{array}$ & $0,8^{\mathrm{a}}$ & 2,3 & 2,6 & 2,6 & 4,6 \\
\hline \begin{tabular}{l}
\multicolumn{1}{c}{ B } \\
Adj. oleoso com \\
immunostin
\end{tabular} & 1,3 & 2,7 & 3,1 & 2,9 & 4,5 \\
\hline $\begin{array}{c}\mathrm{C} \\
\text { Adjuvante } \mathrm{Al}_{2}(\mathrm{OH})_{3}\end{array}$ & 0 & 0,5 & 0,5 & 0,4 & 0,7 \\
\hline $\begin{array}{l}\text { D } \\
\text { Adj. } \mathrm{Al}_{2}(\mathrm{OH})_{3} \text { com } \\
\text { immunostin }\end{array}$ & 0 & 2,5 & 2,7 & 2,2 & 2,9 \\
\hline
\end{tabular}


Tabela 3 - Porcentagem de animais com títulos de anticorpos neutralizantes, maiores ou iguais a $3 \log 2$, induzidos pelas vacinações.

\begin{tabular}{|c|c|c|c|c|c|}
\hline \multirow[t]{3}{*}{ Vacina } & \multicolumn{5}{|c|}{ Coleta } \\
\hline & $1^{\underline{\underline{a}}}$ & $2^{\mathrm{a}}$ & $3^{\underline{a}}$ & $4^{-\mathrm{a}}$ & $5^{\mathrm{a}}$ \\
\hline & $\begin{array}{l}30 \text { dias } \\
\text { após a } 1^{-a} \\
\text { dose }\end{array}$ & $\begin{array}{l}07 \text { dias } \\
\text { após a } 2^{\mathrm{a}} \\
\text { dose }\end{array}$ & $\begin{array}{l}14 \text { dias } \\
\text { após a } 2^{\text {a }} \\
\text { dose }\end{array}$ & $\begin{array}{l}\text { 21dias } \\
\text { após a } 2^{\mathrm{a}} \\
\text { dose }\end{array}$ & $\begin{array}{c}30 \text { dias } \\
\text { após a } 3^{\text {a }} \\
\text { dose }\end{array}$ \\
\hline $\mathrm{A}$ & 20 & 40 & 50 & 50 & 90 \\
\hline Adjuvante Oleoso & & & & & \\
\hline B & 22,2 & 55,5 & 55,5 & 44,4 & 100 \\
\hline $\begin{array}{l}\text { Adj. Oleoso + } \\
\text { Immunostin }\end{array}$ & & & & & \\
\hline $\mathrm{C}$ & 0 & 0 & 10 & 0 & 10 \\
\hline $\begin{array}{l}\text { Adjuvante } \quad \mathrm{Al}_{2} \\
(\mathrm{OH})_{3}\end{array}$ & & & & & \\
\hline $\mathrm{D}$ & 0 & 30 & 55,5 & 30 & 60 \\
\hline $\begin{array}{l}\text { Adj. } \mathrm{Al}_{2}(\mathrm{OH})_{3}+ \\
\text { Immunostin }\end{array}$ & & & & & \\
\hline
\end{tabular}

com STRAUB \& MAWHI-NNEY (1988), os quais relatam que após a vacinação para IBR/IPV com esquema de três doses, os anticorpos são mais persistentes. Pela análise de regressão polinomial para cada vacina, obteve-se ajuste linear apenas para $\mathrm{A}$ e $\mathrm{B}$, pois foram as únicas vacinas que induziram a produção crescente de anticorpos proporcionais às repetições das vacinações.

A porcentagem de animais com altos títulos de anticorpos resultantes das vacinas A e B, permite apenas inferir sobre a provável proteção conferida por elas, uma vez que não foi realizado teste de desafio nos animais vacinados. Essas vacinas, possivelmente, seriam capazes de impedir surtos ou de reduzir a severi-

cia e outros efeitos colaterais sistêmicos (FRERICHS et al., 1982; FENNER et al., 1993; FERNANDEZ et al., 1993).

Pela estreita relação existente entre o BHV1 e BHV-5, a discussão dos resultados obtidos com as vacinas produzidas com o BHV-5, neste experimento, será baseada em resultados de estudos com vacinas para o BHV-1. As quatro vacinas testadas foram consideradas seguras, pois nenhum animal vacinado demonstrou reações localizadas ou sistêmicas indesejáveis.

Após a terceira dose, as vacinas A e B, induziram títulos de anticorpos neutralizantes iguais ou superioes a $3 \log 2$ em $90 \%$ e 100\% dos animais vacinados, respectivamente. $\mathrm{O}$ desempenho das vacinas A e B assemelha-se aos relatos de ZUFFA \& FEKETEOVÁ (1980) e ZUFFA et al. (1985), avaliando vacinas inativadas para $\mathrm{BHV}-1$ com adjuvante oleoso, que resultaram numa imunidade caracterizada por altos títulos de anticorpos neutralizantes e também por uma produção regular de anticorpos secretores. As vacinas A e B, após a terceira dose, induziram altos títulos de anticorpos neutralizantes. As médias foram de 4,6 Log 2 para A e 4,5 para B. Segundo experimentos de LAZAROWICZ et al. (1983), títulos iguais ou superiores a $3 \log 2$, conferem proteção em testes de desafio com amostras virulentas de BHV-1, podendo, entretanto, ocorrer a manifestação de sinais respiratórios leves e transitórios em alguns animais.

Os resultados obtidos com as vacinas A e B demonstram que o crescimento linear dos títulos de anticorpos é dependente da dose e estão de acordo com os trabalhos de MOR-ZARIA et al., (1979), nos quais os bovinos vacinados apresentaram títulos significativos somente após duas doses de vacina, e dade das manifestações clínicas. Além disso, considerando os aspectos epidemiológicos, o fato de mais de $80 \%$ do rebanho apresentar um bom nível de imunidade humoral, reduz a possibilidade do vírus disseminar-se e produzir surtos da doença ou doença de curso fatal.

Também pode-se inferir que os anticorpos induzidos pelas vacinas A e B, possivelmente também se encontram nas secreções nasais. Os anticorpos da classe IgG resultam de exudação do soro e os da classe IgA resultam de linfócitos B sensibilizados pelo antígeno vacinal, que migram para a mucosa nasal onde se fixam, diferenciando-se em plasmócitos produtores de IgA secretora. Experimentos complementares devem ser realizados com o objetivo de pesquisar a presença de anticorpos nas secreções nasais de animais vacinados com a vacina oleosa.

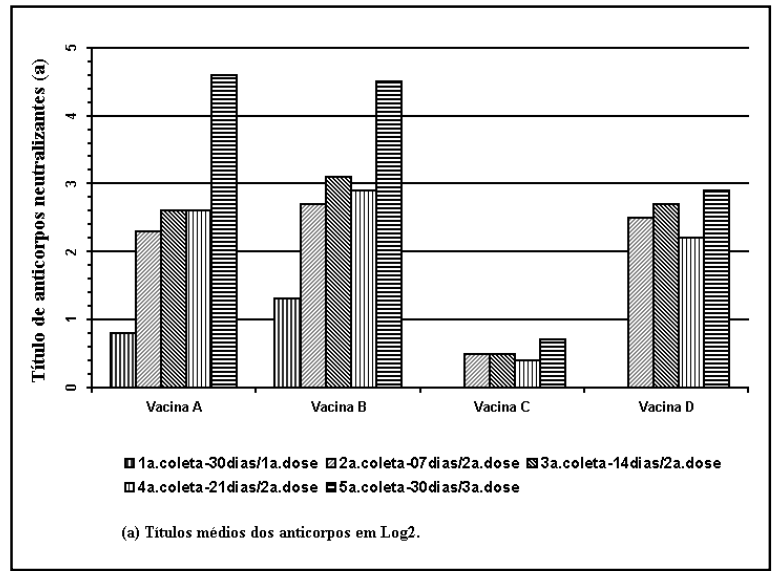

Figura 1. Resposta humoral pós vacinal em bovinos vacinados com as quatro vacinas inativadas.

Ciência Rural, v. 30, n. 5, 2000. 
A relação entre a resposta imune humoral e celular e proteção ao BHV-1 e BHV-5 ainda é um assunto a ser elucidado. Tem sido relatado que a imunidade celular é de maior importância no combate às infecções por herpesvírus, enquanto os anticorpos neutralizantes teriam um importante papel na prevenção da recrudescência da infecção. Sabe-se que a imunidade celular é mais precoce que a humoral, atingindo o pico máximo em uma semana pósinfecção, enquanto os anticorpos neutralizantes tornam-se detectáveis a partir do oitavo ou nono dia pós-infecção (FENNER et al., 1993). Nesse experimento, foi constatado que o aparecimento de imunidade humoral para o BHV-1 e BHV-5, após imunização com vacinas inativadas, é lento e dependente de uma forte e repetida estimulação antigênica.

No presente trabalho, foi adicionado Immunostin $^{\circledR}$ às vacinas $\mathrm{B}$ e $\mathrm{D}$, com o objetivo de aumentar a imunogenicidade das vacinas inativadas. A utilização de substâncias à base de frações da parede celular de Mycobacterium estimula principalmente a indução de linfócitos $\mathrm{T} \mathrm{CD}^{+} \mathrm{e}$, por esse motivo, são considerados ótimos adjuvantes para vacinas inativadas que dependem de imunidade celular (FREUND, 1956; ALKEMADE, 1990). No entanto, a ação do imunoestimulante foi significativa somente na vacina com hidróxido de alumínio, não ocorrendo o mesmo com a vacina oleosa. Ao utilizar Immunostin ${ }^{\circledR}$ na vacina oleosa, esperava-se que o desempenho sorológico fosse potencializado. Nos experimentos de ROMERA et al., 1998, com vacinas inativadas para BHV-1 contendo o coadjuvante sulfolipopolissacarideo (SLP), 90\% dos animais vacinados desenvolveram teste linfoproliferativo (LPT) positivo, e a performance das vacinas foi significativamente melhor com esse imunoestimulante.

No presente experimento, foi demonstrada a superioridade das vacinas inativadas oleosas sobre as vacinas inativadas com adjuvante de $\mathrm{Al}_{2}(\mathrm{OH})_{3}$ na indução de resposta sorológica. A vacina $\mathrm{C}$ induziu níveis muito baixos de anticorpos (média de 0,42 $\log 3$ ) e a vacina D induziu níveis um pouco mais elevados (média de 2,06 Log3), possivelmente devido à adição de Immunostin $^{\circledR}$ na sua formulação. Nenhum dos animais que recebeu as vacinas com adjuvante $\mathrm{Al}_{2}(\mathrm{OH})_{3}$ reagiu sorologicamente nos primeiros 15 dias após a vacinação, e aos 30 dias os animais apresentaram percentuais médios de reagentes muito baixos. Esses resultados diferem dos relatados por LAZAROWICZ et al. (1983), com vacinas com adjuvante de $\mathrm{Al}_{2}(\mathrm{OH})_{3}$ que induziram altos títulos de anticorpos neutralizantes.

Experimentos visando a avaliar a segurança e eficiência de vacinas inativadas para IBR/IPV, disponíveis para comercialização, têm demonstrado indução de imunidade capaz de impedir a manifesta- ção da doença clínica (ZUFFA et al., 1985; ZUFFA \& FEKETEOVÁ, 1980; STRAUB \& MAWHINNEY, 1988), ou minimizar significativamente o seu curso (MORZARIA et al., 1979; FERNÁNDEZ, 1993), uma vez que nenhum tipo de vacina impede a infecção pelo BHV-1 e BHV-5.

Deve-se considerar ainda que a imunização contínua de rebanhos infectados pelo BHV-1 ou BHV-5, aliada a um manejo de gradual substituição dos animais vacinados e controle sorológico dos não vacinados pode, a médio prazo, resultar em um rebanho sorologicamente negativo para o herpesvírus bovino (ZUFFA et al., 1985).

\section{AGRADECIMENTOS}

Agradecemos à FAPERGS pelo apoio financeiro e ao técnico do Laboratório de Imunologia e Virologia, José Carlos Sandrini, pela colaboração na realização deste trabalho.

\section{REFERÊNCIAS BIBLIOGÁFICAS}

ALICE, F.J. Isolamento do vírus da rinotraqueíte infecciosa bovina (IBR) no Brasil. Vet Bras Biol, v.38, n.4, p.919-920, 1978.

ALKEMADE, S.J. The clinical use of immune stimulants in large animals. Ontário, Canadá : Vetrepharm Research, 1990. 08p. Boletim Técnico.

ANUNCIAÇÃO, A V.M., LEITE, R.C., MOREIRA,E.C. Presença de anticorpos para o herpesvírus bovino tipo 1 (BHV1) em bovinos nos Estados de Minas Gerais, Goiás e Rio de Janeiro, através da prova de hemaglutinação passiva. Arq Bras Med Vet Zoot, v.41, n.5, p.433-441, 1989.

FENNER, F.J., GIBBS, E.P., MURPHY, F.A. Veterinary virology. 2 ed. San Diego : Academic, 1993. Cap. 8. p.137-158; cap.9, p.159-178; cap.13, p.241-264; cap.19, p.337-368.

FERNÁNDEZ, F. Enfermedades virales del bovino: complejo respiratorio y diarreico - imunoprofilaxis. In: VIROLÓGICA 93, Porto Alegre, RS. Programas e Resumos... Porto Alegre: Sociedade Brasileira de Virologia, 1993. p.127-130

FLORES, E.F., SILVA, A.M., WEIBLEN, R. Neuropatogenicidade do herpesvírus bovino tipo 5 (HVB-5). In: SIMPÓSIO INTERNACIONAL SOBRE HERPESVÍRUS BOVINO (TIPO 1 E 5) E VÍRUS DA DIARRÉIA VIRAL BOVINA (VBDV), 1998, Santa Maria, RS. Anais... Santa Maria, RS, Brasil: Pallotti, 1998. 175p. p.127-137.

FRERICHS, G. N.; WOODS, S. B., LUCAS, M.H., et al. Safety and efficacy of live and inactivated infectious bovine rhinotracheitis vaccines. Vet Rec, v.111, p.116-122, 1982.

FREUND, J. The mode of action of immunological adjuvants. Adv Tuberc Res, v.7, p.130-148, 1956.

HALFEN, D.C., CARDOSO, C. M., VIDOR, T., et al. Isolamento de herpesvírus bovino 1 (BHV-1) em surto de vulvovaginite. In: CONGRESSO BRASILEIRO DE MICROBIOlOGIA, 18, 1995, Santos, SP. Programas \& Resumos... Sociedade Brasileira de Microbiologia, 1995. p.135. 
HOUSE, J.A., BACKER, J. A. Bovine herpesvirus IBR - IPV the antibody virus neutralization reaction. Cornell Vet, v.61, p.320-335, 1971.

KUNG, D.C., LANGONI, H., SAVOLDI, F. Serological survey of infectious bovine rhinotracheitis - IBR antibodies detection. In: PANVET, 15, 1996, Campo Grande. Abstracts.... Campo Grande: Panamerican Association of Veterinary Sciences, 1996. p.287, PN9, n.1260.

LAZAROWICZ, M.V., STECK, F., ACKERMANN, M., $\boldsymbol{e} t$ al. Prüfung von zwei impfstoffen gegen die infectióse bovine rhinotracheitis. Schweiz Arch Tierheilk, v.25, p.797$808,1983$.

LOVATO, L.T., WEIBLEN, R., TOBIAS, F.L., et al. Herpesvírus bovino tipo 1 (BHV-1): inquérito soroepidemiológico no rebanho leiteiro do Estado do Rio Grande do Sul, Brasil. Ciência Rural, v.25, n.3, p.425430, 1995.

MAYR, A.,GUERREIRO, M.G. Virologia veterinária. 2.ed. Porto Alegre : Sulina, 1981. 472p.

MAYR, A., BACHMANN, P.A., BIBRACK, B.M., $\boldsymbol{e} \boldsymbol{t} \boldsymbol{a l}$ Virologische arbeitsmethoden, Band IV - Sicherheit bei virologischen Arbeiten - Biometrische Methoden. Stutgart: Gustav Fischer Verlag, 1982. 662p.

MORZARIA, S.P.,RICHARDS, M.S.,HARKNESS, J.W., et al. A field trial with a multicomponent inactivated respiratoty viral vaccine. Vet Rec, v.105, p.410-414, 1979.

MULLER, S.B.K., IKUNO, A.A., CAMPOS, M.T., et al. Ocorrências simultâneas de alterações respiratórias e genitais associadas à rinotraqueíte infecciosa dos bovinos/ vulvovaginite pustular infecciosa (IBR/IPV). Arq Inst Biológico, São Paulo, v.45, n.3, p.55-60, 1979.

NOGUEIRA, F.R.C., CAMARGO, A. J.R., RESENDE, D.A Ocorrência de rinotraqueíte infecciosa/vulvo-vaginite pustular infecciosa bovina no estado do Rio de Janeiro. Rio de Janeiro : Pesagro-RIO, 1986. p. 1-5. Comunicado técnico n. 167

RIET-CORREA, F., MOOJEN, V., ROEHE, P.M., et al Viroses confundíveis com febre aftosa: Revisão bibliográfica. Ciência Rural, v.26, p.323-332, 1996.

RIET-CORREA, F., VIDOR T., SCHILD, A.L., et al. Meningoencefalite e necrose do córtex cerebral em bovinos causadas por herpesvírus bovino-1. Pesq Vet Bras, v.9, p.13$16,1989$.
ROIZMAN, B., DESROSIERS, R.C.; FLECKENSTEIN, R.; $\boldsymbol{e}$ al. Family Herpesviridae. Arch Virol, Supl,10, p.114127, 1995.

ROEHE, P.M., TEIXEIRA, M.B., ESTEVES, P. A., et al. Situação do BHV-1 e BHV-5 no Brasil. In: SIMPÓSIO INTERNACIONAL SOBRE HERPESVÍRUS BOVINO (TIPO 1 E 5) E VÍRUS DA DIARRÉIA VIRAL BOVINA (BVDV), 1998, Santa Maria, RS. Anais... Santa Maria, RS: Pallotti, 1998. 175p. p.89-96.

ROMERA, S., PUNTEL, M., ZAMORANO, P., et al. Different vaccines against $\mathrm{BHV}-1$ : a long term evaluation of the immune response induced in calves. In: SIMPÓSIO INTERNACIONAL SOBRE HERPESVÍRUS BOVINO (TIPO 1 E 5 ) E VÍRUS DA DIARRÉIA VIRAL BOVINA (VDVB), 1998, Santa Maria, RS. Anais... Santa Maria, RS: Pallotti, 1998. 175p. p.157.

STRAUB, O C., MAWHINEY, I.C. Vaccination to protect calves against infectious bovine rhinotracheitis. Vet Rec, v.122, p.407-411, 1988.

VIDOR, T. FAPERGS - Relatório de atividades, 1993/1995. Pelotas, RS, 1995. 18p.

VIDOR, T., HALFEN, D.C., LEITE, E. et al. Herpes bovino tipo 1 (BHV-1):I. Sorologia de rebanhos com problemas reprodutivos. Ciência Rural, v.25, n.3, p.421-424, 1995.

WEIBLEN, R., BARROS, L.C.S., CANABARRO, T.F., $\boldsymbol{e}$ t al. Bovine meningoencephalitis from IBR virus. Vet Rec, v.24, p.666-667, 1989.

WEIBLEN, R., KREUTZ, L.C., CANABARRO, T. F. et al. Balanoposthitis in bulls due to bovine herpesvirus in South Brazil. J Med Biol Res, v.24, n.8, p.773-775, 1991.

ZONTA, E.P., MACHADO, A.A., SILVEIRA JÚNIOR, P. Sanest - Sistema de análise estatística. Manual do Usuário. Pelotas : UFPel, 1984. 118p.

ZUFFA, A ., FEKETEOVÁ, N. Protection of cattle vaccinated with inactivated oil -adjuvant IBR - vacine against experimental infection. Zbl Vet Med B, v.27, p.725-733, 1980.

ZUFFA, A., ZUFFA, T., ZAJAC, J. Study of immunity induced by the inactivated oil - adjuvant vaccine after natural infection with the virus of infectious bovine rhinotracheitis (IBR) in cattle. Zbl Vet Med B, v.32, p.724-735, 1985. 